\title{
Extension Contracture Post Total Knee Replacement: A Case Report
}

\author{
Sholahuddin Rhatomy ${ }^{1 *}$, Faiz Alam Rasyid ${ }^{2}$ \\ ${ }^{1}$ Department of Orthopedics and Traumatology, Dr. Soeradji Tirtonegoro General Hospital, Klaten, Indonesia; ${ }^{2}$ Soeradji \\ Tirtonegoro Sport Center and Research Unit, Dr. Soeradji Tirtonegoro General Hospital, Klaten, Indonesia
}

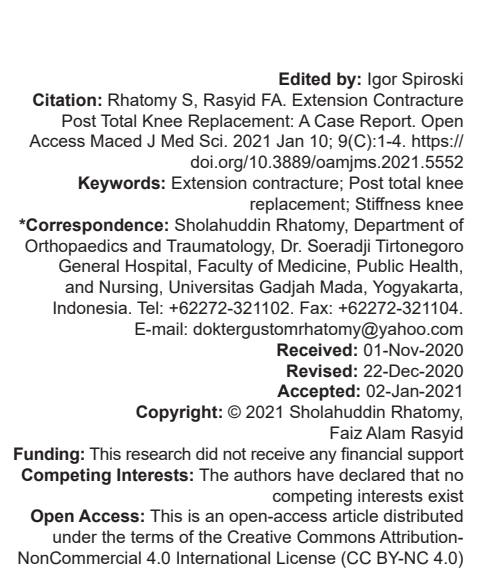

Introduction

Stiffness is a common problem after knee arthroplasty, causing up to $58 \%$ for further procedure (such as manipulation under anesthesia). Patients who experience this problem usually have poor outcome. Sometimes patients with stiff knee complained of having persistent knee pain, and this symptom often persists despite either non-operative or operative measures [1].

Arthrofibrosis of the knee is characterized by proliferation of fibrous tissue and causes limited motion to the knee and sometimes pain. The initial phase is marked by an increase in pro-inflammatory mediators that will stimulate myofibroblasts and mast cell proliferation, and increase type-I collagen deposition which ultimately leads to subsequent joint contractures. Until now, there is no formal definition on joint contractures. Therefore, the diagnosis is based on clinical examination which includes restriction in range of motion (ROM) of the joint [1]. From various literature, it is found that the definition of contracture varies widely but the agreed condition is the limited ROM. The terms "limited range of motion," "stiffness," "contracture," and "arthrofibrosis" are often used widely in the various literature to describe limitation of knee motion. This lack of consensus has led to a wide range of prevalence, from $0 \%$ to $54 \%$ [2].

There is no consensus on the degree of restriction regarding $\mathrm{ROM}$ in stiff knee after arthroplasty [2], [3]. Nicholls and Dorr [4] stated that stiffness post knee arthroplasty is a flexion contracture more than $20^{\circ}$ or $<45^{\circ}$ in knee ROM. Scranton [2] defines that stiffness is a condition of knee ROM $<90^{\circ}$. Christensen et al. [5] defined that stiffness is a condition of $\mathrm{ROM}<70^{\circ}$ in either active or passive flexion. Nevertheless, this definition does not include a flexion deficit, so it focuses on the lack of extension [2], [3].

Flexion contracture is the most reported case in most case reports; however, we reported a rare case of patient with extension contracture after total knee arthroplasty (TKA).

\section{Presentation of Case}

A 62-year-old woman was presented with a 3-month history of right TKA using posterior stabilized type. She was a housewife and her body mass index was 
$27.34 \mathrm{~kg} / \mathrm{m}^{2}$ and did not have any comorbid. Patient did not attend physiotherapy program as prescribed due to the fear of visiting hospital during COVID-19 pandemic. After 3 month she came to the hospital and complained that she could not flex the knee. Nevertheless, she could still walk (Figure 1).

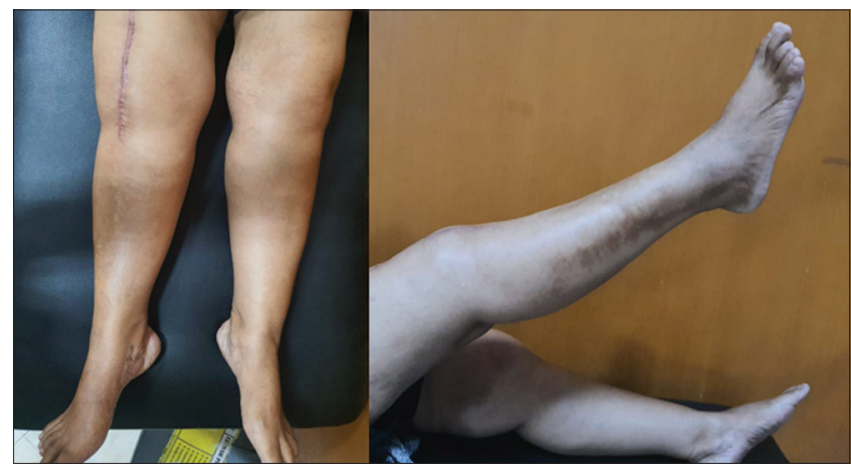

Figure 1: Fixed extension contracture

Based on examination, there was no tenderness on the knee. On the right knee, there was quadriceps hypotrophy. The patella was palpable at the medial side of the femoral condyle. It had no mobility. There was no active and passive ROM, because it was fixed at $0^{\circ}$. Knee radiography showed that the implant of arthroplasty was well seated with normal tibiofemoral angle (Figure 2).

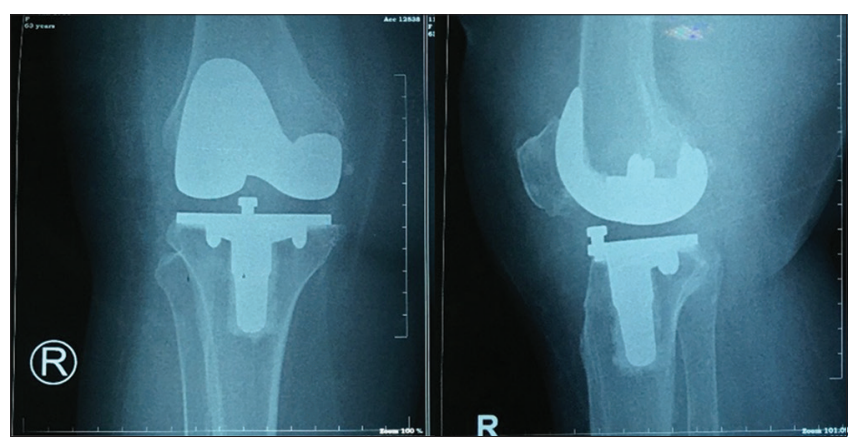

Figure 2: Anteroposterior and lateral view of knee X-ray

\section{Operation}

Under anesthesia, we evaluate the ROM, and the knee was fixed in $0^{\circ}$ extension. We performed medial parapatellar approach for knee arthrotomy (Figure 3) and we added lateral parapatellar arthrotomy to release the contracture (Figure 4). The fibrotic tissues were removed. The flexion and extension of the knee were evaluated and we managed to get $0-130^{\circ}$ of flexionextension ROM (Figure 5). Afterward, the wound was closed and a single drain was placed.

\section{Post-operation}

In the ward, the patient was treated using continuous passive motion (CPM) for 1 week and the CPM was maintained within the range of $0-130^{\circ}$.

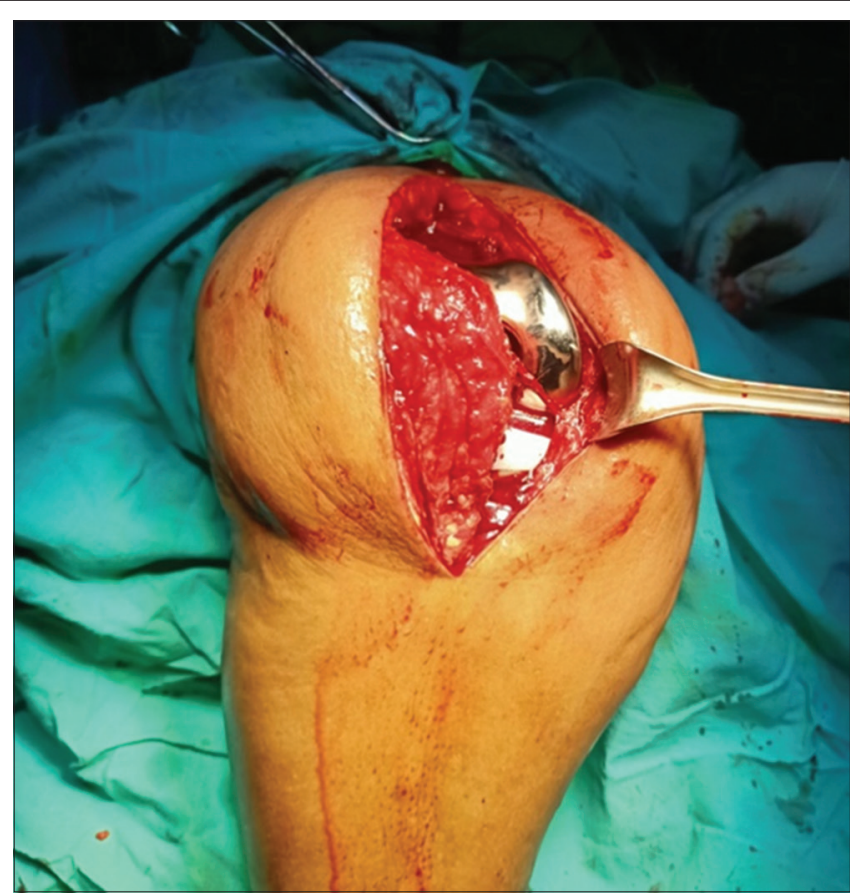

Figure 3: Medial parapatellar arthrotomy

\section{Rehabilitation program}

The patient was allowed to do full weight bearing with the help of walker, and was trained to strengthen the quadriceps muscle. The patient also performed passive and active ROM exercise.

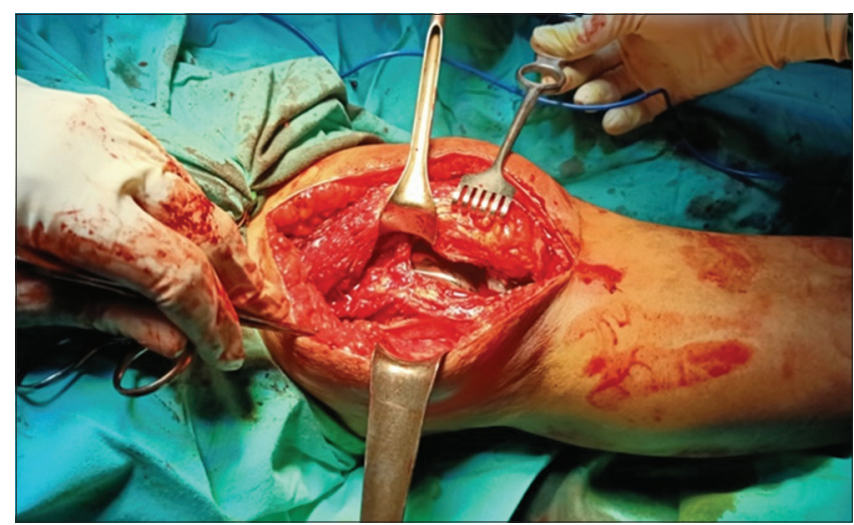

Figure 4: Lateral parapatellar arthrotomy

\section{Six months follow-up}

Six months after surgery, the patient could walk normal with $\mathrm{ROM}$ ranged between $0^{\circ}$ and $100^{\circ}$ (Figure 6 ).

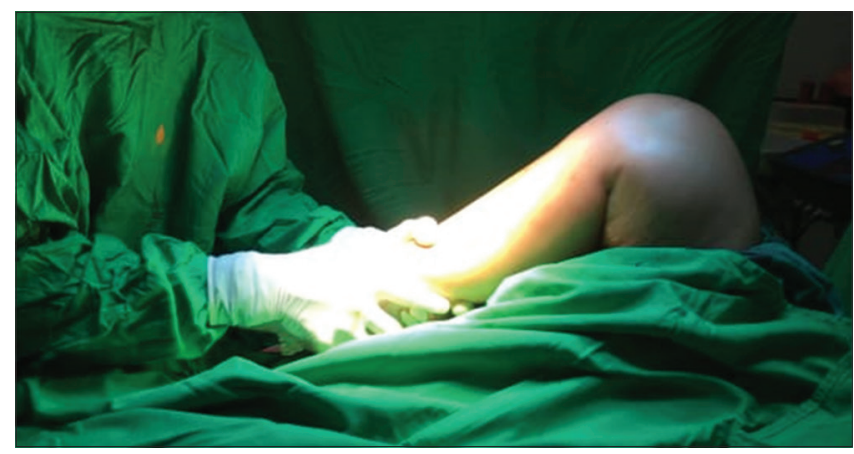

Figure 5: Achievement of full flexion of the knee 


\section{Discussion}

There are various causes of stiffness after arthroplasty, such as preoperative limited knee motion, improper position of the arthroplasty pre-operative, infection, improper bone resection, tight posterior cruciate ligament, instability of the implant, large size of the femoral implant or patella, heterotopic ossification, patellofemoral problem, high of knee joint line, loosening of components, reflex sympathetic dystrophy, post-operative pain management, poor post-operative rehabilitation or poor patient compliance [5].

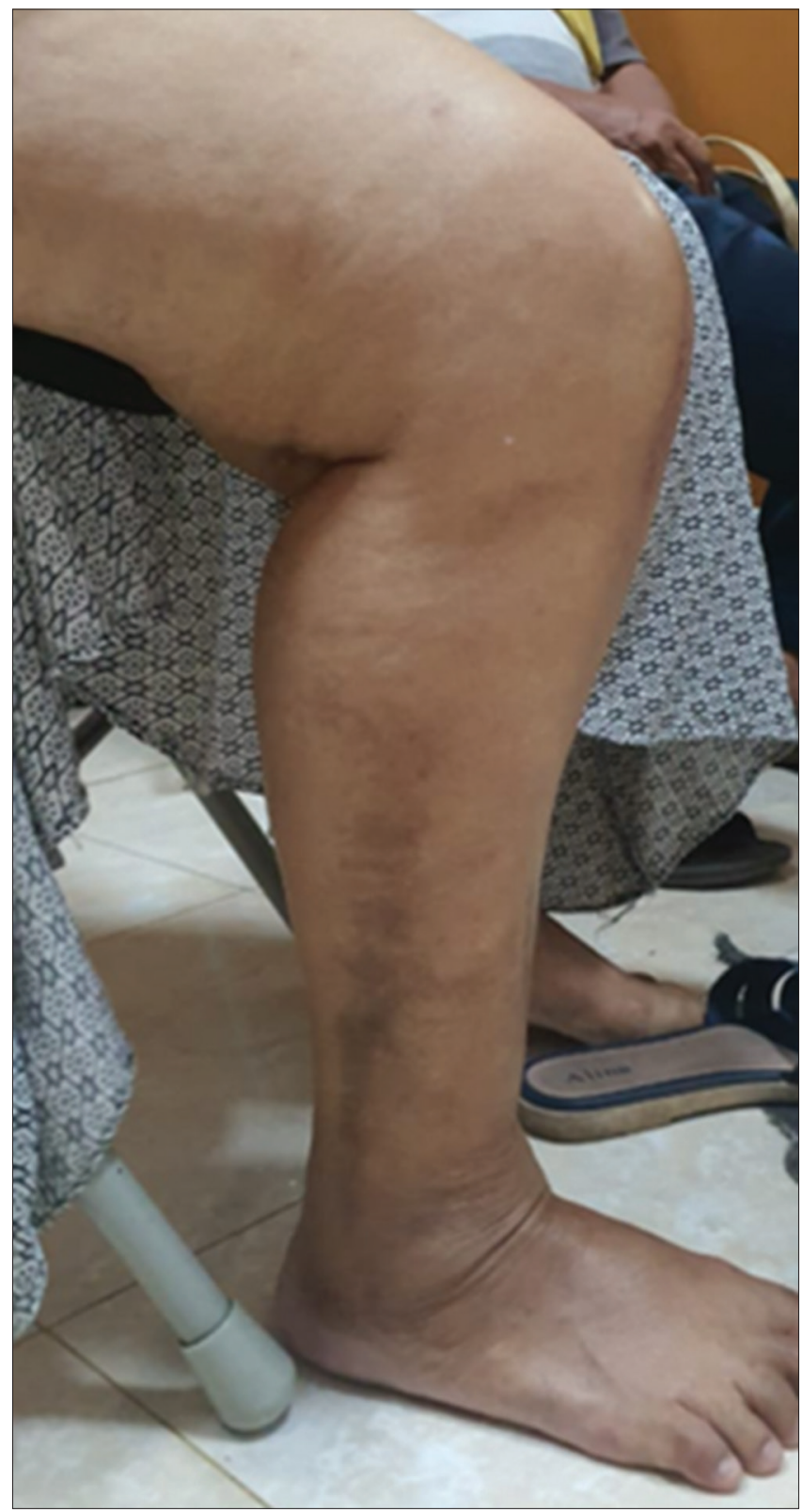

Figure 6: Final follow up

Knowledge of the pre-operative and intraoperative ROM enables clinicians and patients to have an overview of the post-operative ROM and this will guide the rehabilitation program [3], [6]. ROM is evaluated periodically and if at the time of evaluation the desired ROM is not achieved, aggressive physiotherapy will be performed. Closed manipulation under anesthesia can be done 4-6 weeks after surgery before the scars mature. Closed manipulations can also be performed 8 weeks after surgery but it has high risk of failure and increase risk of fracture. If closed manipulation is unsuccessful, arthroscopy can be performed to remove all of intra-articular fibrous tissue under anesthesia [3], [6]. However, this debridement arthroscopy must be done carefully, because it can cause infection.

In our case, the patient still could not flex the knee even though she had already followed rehabilitation program. We decided to performed surgery 3 months after rehabilitation program due to its failure. We performed medial and lateral parapatellar arthrotomy, by this approach, the patella could be easily mobilized and the knee could be flexed until $90^{\circ}$. After all fibrous in the knee joint was removed; we performed knee manipulation under anesthesia, with gradual flexion and knee extension, until we achieved ROM from $0^{\circ}$ to full degree of flexion.

Following the patient in the ward, continuous passive movement was prescribed immediately and it was set for $0-120^{\circ}$ for a week. The use of CPM has always been debated according the prevention of stiffness, because there has been inconclusive evidence of its ability to improve ROM and inconclusive evidence of reducing the need for further procedure (Movement Under Aanesthesiology (MUA) or arthrotomy) [7]. In a Cochrane review of 24 randomized controlled trials, it was showed that CPM proved only a modest difference in active knee flexion [8]. Boese et al. [9] performed a comparison among group who received a CPM moving from $0^{\circ}$ to $110^{\circ}$, a group with CPM that was fixed at $90^{\circ}$ in flexion, and a group who did not receive a CPM. They concluded that there was no difference between the three groups for post-surgery ROM [9].

Several studies reported excellent outcome in patients who underwent open arthrotomy to increase ROM. A retrospective study by Millett et al. reported improvement in knee ROM, with increase degree of flexion from $81^{\circ}$ to $125^{\circ}$ and decrease degree of extension from $18.8^{\circ}$ to $1.25^{\circ}$. The Lysholm score was improved and all patients were satisfied with their outcomes [10].

\section{Conclusion}

Stiff knee is a common problem after TKA. Close observation and proper rehabilitation can prevent stiff knee. Close manipulation, manipulation under anesthesia, arthroscopy debridement, and open contracture release are the option of this problem. 


\section{Ethical Approval}

Written informed consent was obtained from the patient for publication of this case report and accompanying images.

Ethical Approval No KE/FK/0193/EC/2020 from Medical and Health Research Ethics Committee, Faculty of Medicine, Public Health and Nursing, Universitas Gadjah Mada, Yogyakarta, Indonesia

\section{Acknowledgment}

We thank Erik Christopher with his help during manuscript preparation

\section{References}

1. Tibbo ME, Limberg AK, Salib CG, Ahmed AT, Van Wijnen AJ, Berry DJ, et al. Acquired idiopathic stiffness after total knee arthroplasty: A systematic review and meta-analysis. J Bone Joint Surg Am. 2019;101(14):1320-30. https://doi.org/10.2106/ jbjs.18.01217

PMid:31318813

2. Scranton PE. Management of knee pain and stiffness after total knee arthroplasty. J Arthroplasty. 2001;16(4):428-35. https://doi. org/10.1054/arth.2001.22250

PMid:11402404

3. Manrique J, Gomez MM, Parvizi J. Stiffness after total knee arthroplasty. J Knee Surg. 2015;28(2):119-26. https://doi. org/10.1055/s-0034-1396079

PMid:25513992

4. Nicholls DW, Dorr LD. Revision surgery for stiff total knee arthroplasty. J Arthroplast. 1990;5:S73-7. https://doi. org/10.1016/s0883-5403(08)80029-0

PMid:2243220

5. Christensen LC, Crawford JJ, Olin MD, Vail TP. Revision of the stiff total knee arthroplasty. J Arthroplasty. 2002;17(4):409-15. https://doi.org/10.1054/arth.2002.32105 PMid:12066268

6. Kim GK, Mortazavi SM, Purtill JJ, Sharkey PF, Hozack WJ, Parvizi J. Stiffness after revision total knee arthroplasty. J Arthroplasty. 2010;25(6):844-50. https://doi.org/10.1016/j. arth.2010.04.001

PMid:20570101

7. Thompson R, Novikov D, Cizmic Z, Feng JE, Fideler $\mathrm{K}$, Sayeed Z, et al. Arthrofibrosis after total knee arthroplasty: Pathophysiology, diagnosis, and management. Orthop Clin North Am. 2019;50(3):269-79. https://doi.org/10.1016/j. ocl.2019.02.005

PMid:31084828

8. Harvey LA, Brosseau LH. Continuous passive motion following total knee arthroplasty in people with arthritis. Cochrane Database Syst Rev. 2010;3:CD004260. https://doi. org/10.1002/14651858.cd004260.pub2 PMid:24500904

9. Boese CK, Weis M, Phillips T, Lawton-peters S, Gallo T, Centeno $L$. The efficacy of continuous passive motion after total knee arthroplasty: A comparison of three protocols. J Arthroplasty. 2014;29(6):1158-62. https://doi.org/10.1016/j. arth.2013.12.005 PMid:24412145

10. Millett PJ, Williams RJ $3^{\text {rd }}$, Wickiewicz TL. Open debridement and soft tissue release as a salvage procedure for the severely arthrofibrotic knee. Am J Sports Med. 1999;27(5):552-61. https://doi.org/10.1177/03635465990270050201

PMid:10496569 